\title{
Materiales de obturación radicular utilizados en dientes deciduos
}

Trejo- $A^{1}$

Cuevas- $C^{2}$

\section{Resumen}

La caries y traumatismos son las principales causas de urgencias en odontología pediátrica. Estas afecciones pueden llegar a ejercer un daño irreversible en el tejido pulpar comprometiendo la permanencia de los órganos dentarios afectados. Para limitar el daño pulpar y evitar la extracción de piezas temporales se han diseñado distintas técnicas que van desde recubrimientos pulpares hasta un tratamiento más radical como la pulpectomía. Ésta última consiste en la extirpación del tejido pulpar, la limpieza y desinfección del sistema de conductos y la obturación de los mismos. Diversos autores han descrito las características ideales que debe presentar un material obturador de conductos de la dentición temporal, en los que se incluyen actividad bactericida y bacteriostática, adecuado sellado tridimensional, biocompatibilidad y reabsorción del material a una velocidad similar que las raíces. Desde hace largo tiempo se han desarrollado diversos materiales para cumplir con las exigencias que demanda la técnica. Dentro de los primeros materiales surgidos con éste propósito se encuentran el Óxido de Zinc con Eugenol, Hidróxido de Calcio y materiales a base de yodoformo, con el tiempo surgieron combinaciones de estos materiales para aumentar las ventajas y disminuir las desventajas. De éstos, las pastas yodoformadas con Hidróxido de Calcio son los que han tenido mayor aceptación.

Palabras clave: dientes deciduos, pulpa.

Artigo de revisão

\section{Material obturação do canal radicular em dente decíduos}

\section{Resumo}

Cárie e trauma são as principais causas de emergências em odontopediatria. Essas condições podem levar a danos irreversíveis ao tecido pulpar comprometendo a manutenção dos dentes envolvidos. A perda precoce de dentes decíduos acarreta vários problemas na dentição permanente, como giroversões, migração mesial, hábitos lin- guais viciosos e outros. Para limitar os danos pulpares e evitar a exodontia de dentes decíduos, são propostas diferentes técnicas, desde capeamentos pulpares até tratamentos mais radicais, como a pulpectomia. Esta última envolve a remoção do tecido pulpar, limpeza e desinfecção dos canais e sua obturação. Embora este procedimento tenha muitas semelhanças com a técnica endodôntica convencional para dentes permanentes apresen-

\footnotetext{
${ }^{1}$ CD, Alumno de la Especialidad en Endodoncia. Facultad de Odontología. Universidad Autónoma del Estado de México. 
ta certas dificuldades características de dentes decíduos, tais como a complexa morfologia dos canais radiculares, a reabsorção radicular fisiológica e a consequente erupção dos dentes permanente. Vários autores têm descrito as características ideais de um material obturador de canais radiculares de dentes decíduos, que incluem atividade bactericida e bacteriostática, biocompatibilidade e padrão de reabsorção similar a da raiz do dente decíduo. Desde muito tempo, vários materiais têm sido desenvolvidos para cumprir as exigências que essa técnica requer. Dentre os primeiros materiais desenvolvidos com esta finalidade estão a pasta de óxido de zinco e eugenol, hidróxido de cálcio e materiais a base de iodoformio. Com o tempo surgiram combinações destes materiais para aumentar suas vantagens e diminuir suas desvantagens. Pastas de iodofórmio em combinação com hidróxido de cálcio são as que têm tido maior aceitação.

Palabras chave: dentes decíduos, polpa.

\section{Review article}

\section{Root canal filling material in deciduos teeth}

\section{Abstract}

Caries and trauma are the main causes of emergencies in pediatric dentistry. These conditions can lead to trigger irreversible damage to the pulp tissue, compromising the permanence of teeth affected. There are designed different techniques to limit the pulp damage and prevent early tooth loss, these includes treatments like pulp capping and pulpectomy. The latter involves removal of vital or necrotic pulp tissue, cleaning, disinfecting and filling the roots canals system. Several authors have described the ideal characteristics for a root canal filling material in primary tooth, these include antimicrobial properties, adequate sealing, biocompatibility and resorption at a same rate than the roots of the deciduous teeth. Throughout the dental history, a wide variety of materials have been used for root canal filling. Zinc oxide-eugenol cement, calcium hydroxide, and iodoform pastes were first used as root canal filling materials in deciduous teeth. Combinations of these were developed to improve the advantages of each one.
Iodoform pastes in combination with calcium hydroxide are those who have had greater acceptance.

Key words: deciduos teeth, pulp.

\section{Introducción}

Una terapia pulpar tiene como objetivo principal, evitar la extracción de dientes que han sufrido un daño extenso que aún conservan sus funciones. En el caso de la dentición temporal, la conservación de los órganos dentarios, sirve como guía para la erupción de las piezas permanentes, propiciando un adecuado desarrollo de los arcos dentarios.(1-5) La pérdida anticipada de los dientes temporales puede dar lugar a migración mesial de las piezas permanentes, giroversiones en el momento de la erupción, la aparición de hábitos indeseables, dificultad al desarrollar el lenguaje oral y alteraciones de carácter psicológico.(3-7)

Para lograr la conservación del tejido pulpar se han descrito diferentes técnicas y materiales. (1, 
8, 9) Entre estos procedimientos se encuentra la pulpectomía, el cual es un tratamiento que hace referencia a la eliminación del tejido contenido en los conductos radiculares, vital o necrótico; dicho tratamiento abarca también la limpieza, conformación y desinfección del sistema de conductos para su posterior obturación con un material. $(1,2,8,10,11)$

Ésta técnica ha sido ampliamente debatida. Algunos autores señalan que debido a la complicada morfología del sistema de conductos en los órganos dentarios primarios, no se logra un adecuado sellado radicular, incrementando las posibilidades de una infección o reinfección subsecuente a nivel periapical. $(6,11,12)$ La mayor curvatura de las raíces de dientes primarios también dificulta la instrumentación e incrementa el riesgo de perforación, también se ha descrito que los materiales utilizados como obturadores pueden ocasionar daños irreversibles a la dentición secundaria, esto debido a la falta de reabsorción de algunos materiales, afectando el esmalte o impidiendo que la pieza erupcione de forma adecuada. $(11,12)$ Los detractores de ésta técnica sugieren que la extracción y colocación de un mantenedor de espacio es una mejor opción que limita la enfermedad y molestias y previene una infección posterior, sobre todo en pacientes poco cooperadores.(6)

Contrario a esto se han reportado gran cantidad de casos clínicos con un alto grado de éxito en la obturación de conductos radiculares primarios. (4, 11-18) Para realizar tratamientos de este tipo, se han descrito diversos materiales de obturación con distintas propiedades. Si bien ninguno de ellos se considera $100 \%$ exitoso, los resultados clínicos obtenidos hacen de ésta terapia una alternativa válida para la conservación de la integridad de los arcos dentarios.
Etiología y epidemiología de las alteraciones

pulpares

La infección vía endodóntica es el resultado una cadena de eventos que pueden tener su origen en la invasión cariogénica sobre la dentina y la pulpa; en la invasión microbiana desde el periodonto hacia el sistema de conductos; en traumatismos o como resultado del tratamiento odontológico. $(9,10,19,20)$

A pesar de los esfuerzos de diversas instituciones gubernamentales y educativas, así como de los odontólogos, la caries aún tiene una gran incidencia en la población mundial.(26-29) Según datos emitidos por la OMS, la prevalencia de caries en personas en edad escolar es de $60-90 \%$ en todo el mundo.(27) La caries es la enfermedad crónica más común en niños, es de origen multifactorial con acción predominante del Streptococcus mutans; su alta prevalencia la hace un problema de salud pública. $(27,30-33)$

Se han realizado diversos estudios epidemiológicos en diversos sectores de la República Mexicana con la intención de evaluar la prevalencia de caries en niños en edad escolar como los realizados en el estado de Guerrero por Vera Hermosillo y colaboradores,(27) en el que se observó que la incidencia de caries en niños y niñas de 5-10 años fue de $75.51 \%$; en el estado de Sinaloa, Villalobos y colaboradores(30) publicaron en 2006 una incidencia de caries de $90 \%$ en dentición temporal y $82 \%$ en dentición permanente en infantes de 6 a 12 años y en el estado de Campeche, Segovia y colaboradores(31) realizaron un estudio en el que se observó que en una población de niños en edades entre $3-6$ años un porcentaje de $17.9 \%$ presentaban lesiones cariogénicas en los que se ve afectada directamente el tejido pulpar. En el estado de Hidalgo, la caries demostró una incidencia de alrededor de $60 \%$ en infantes de 5 a 12 años.(35-37) 
Por otro lado, las lesiones traumáticas también son bastante comunes en la dentición temporal; se estima que entre el 11 y $30 \%$ ha sufrido algún tipo de trauma dental antes de los 5 años(24); las lesiones se hacen frecuentes por actividades escolares y deportivas, peleas, accidentes automovilísticos o de otra índole. $(24,25)$ Se considera que los niños son más propensos a los traumatismos que las niñas por la mayor actividad vigorosa.(25) Los dientes más propensos a los traumatismos son los incisivos superiores, debido a la posición que ocupan en la arcada(25).

\section{Diagnóstico y plan de tratamiento}

La selección del plan de tratamiento, así como las indicaciones y el objetivo del mismo, deben realizarse bajo una adecuada valoración clínica y radiográfica que determine la vitalidad o no del tejido pulpar. El diagnóstico se debe realizar basado en las siguientes recomendaciones $(1,8)$ :

1. Adecuada historia clínica con historial farmacológico.

2. Historia clínica dental que incluya los signos y síntomas actuales.

3. Interrogatorio a los padres y al paciente que arroje síntomas sobre el padecimiento actual tales como la ubicación, intensidad y duración del dolor.

4. Examinación objetiva de los tejidos intraorales y extraorales.

5. Obtener radiografías de las piezas afectadas, que ayuden al diagnóstico y sirvan para darnos una idea del grado de afectación pulpar, así como muestren evidencia de signos radiográficos que indiquen la presencia de un absceso periapical.
6. Exámenes clínicos tales como palpación, percusión y movilidad. La sensibilidad a la presión o a la percusión es un síntoma que sugiere al menos, cierto grado de afectación pulpar. Se puede determinar la presencia de inflamación de tejidos blandos, ésta inflamación nos puede sugerir un absceso periapical. La movilidad, también suele ser indicativo de afección en la pulpa y pudiendo ser indicativo de infección de los tejidos perirradiculares.

Aún con estas herramientas, el diagnóstico puede ser complicado. La presencia o ausencia de dolor puede no ser coincidente con el grado de inflamación pulpar. En los niños, sobre todo en los más pequeños, las pruebas de palpación, percusión y movilidad, pueden verse alteradas debido a aspectos psicológicos. Además de esto en odontopediatría el examen radiográfico es más complicado. Las pruebas de vitalidad pulpar, tanto eléctricas como térmicas, no son recomendables debido a la aprehensión o miedo de los pacientes pediátricos, pudiendo obtener valores no consistentes con el grado de inflamación pulpar.

Indicaciones y contraindicaciones de una pulpectomía

Con base en los exámenes clínicos y radiográficos, así como una historia clínica completa se pueden determinar las piezas que son candidatas para un tratamiento de pulpectomía $(1,8)$. La Academia Americana de Odontología Pediátrica (AAPD), en su guía para la terapia pulpar de dientes primarios y dientes permanentes inmaduros, describe las siguientes indicaciones y contraindicaciones para realizar una pulpectomía. $(1,8,38,39)$ 

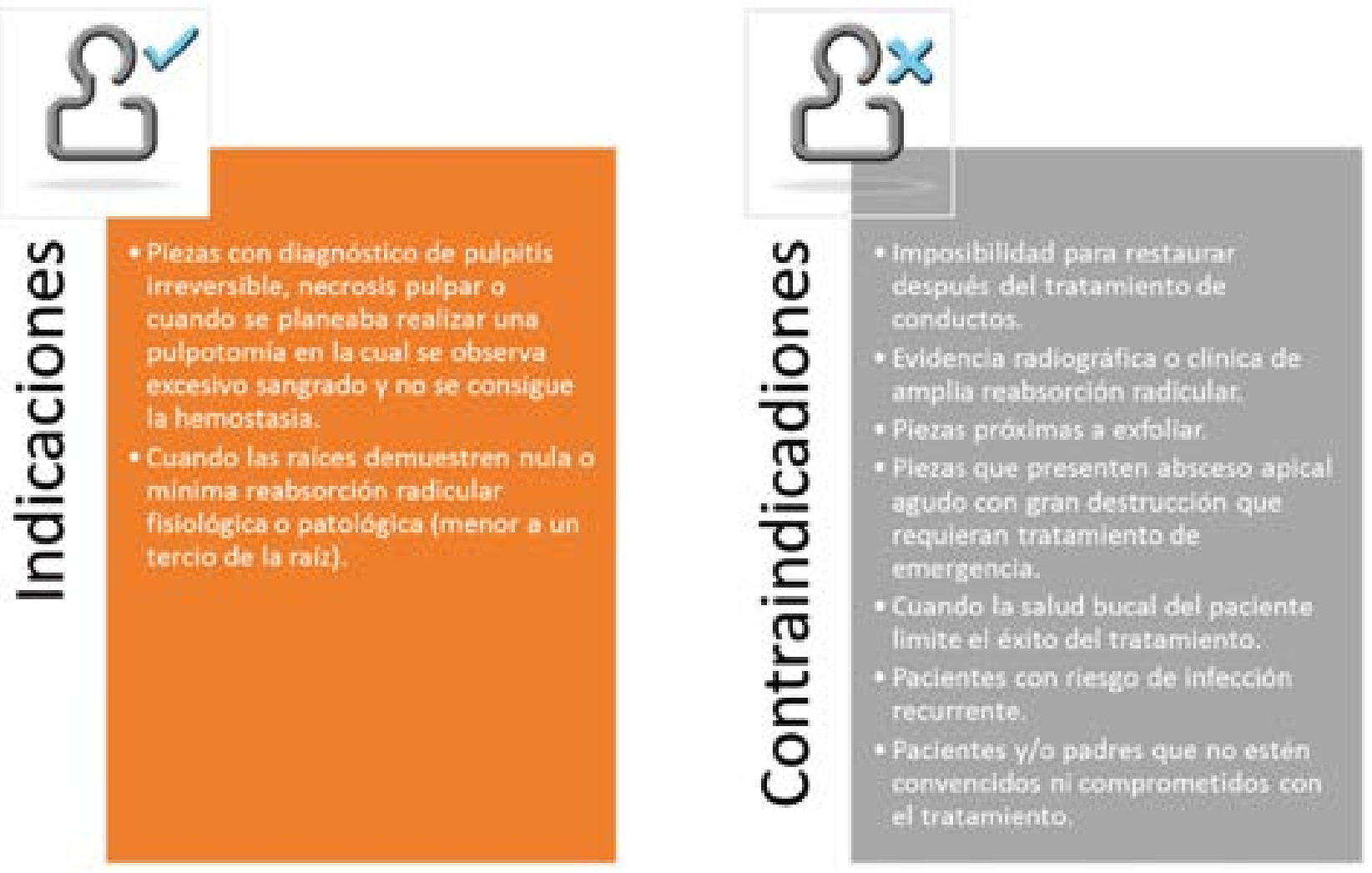

Figura 1. Indicaciones y contraindicaciones para una pulpectomía.

En el caso de pacientes que han sufrido alguna clase de traumatismo, es importante realizar un seguimiento aunque no haya evidencias clínicas ni radiográficas de necrosis, ya que ésta puede tener lugar entre 6-8 semanas después del traumatismo. En todos los casos, el seguimiento debe ser continuo para valorar las condiciones del paciente y el éxito de los tratamientos realizados.

\section{$\underline{\text { Pasos del tratamiento }}$}

Si bien los pasos a seguir durante la realización de una pulpectomía son bastante universales, aún hay puntos en los que no se logra un consenso definitivo dentro de la comunidad odontológica, de tal suerte que se ha debatido sobre si el tratamiento debe realizarse en 1 o 2 sesiones, tampoco existe un consenso sobre la solución irrigadora de elección y menos aún, sobre el agente que deberá obturar el sistema de conductos. $(1-4,8,13,16,38,40)$

1. Radiografía preoperatoria, donde se observen los ápices radiculares.

2. Anestesia local.

3. Colocación de dique de hule.

4. Remoción de tejido con caries.

5. Apertura de la cámara pulpar.

6. Retirar los restos de tejido pulpar cameral, preferentemente con una cucharilla dentinaria.

7. Identificar todos los conductos e irrigar.

8. Realizar la medición de la longitud de los conductos, colocando la lima $2 \mathrm{~mm}$ antes de llegar al ápice. Otros autores manejan que la 
longitud de trabajo debe ser $1 \mathrm{~mm}$ corto del ápice.

9. Realizar un limado gentil, teniendo en cuenta la mayor curvatura de las raíces temporales así como su estreches.

10. Irrigar convenientemente. Éste es un paso vital para la eliminación de la flora bacteriana contenida en el sistema de conductos $(6,7)$. Se han estudiado también distintas substancias irrigadoras, y aunque hoy día la más aceptada y la más empleada es el Hipoclorito de Sodio, no hay un consenso sobre la concentración ideal de éste material. Otras soluciones irrigadoras como Clorhexidina, EDTA y Ácido Cítrico pueden ser utilizadas.(7)

11. Secar los conductos con puntas absorbentes, también teniendo cuidado de colocarlas $2 \mathrm{~mm}$ cortas del ápice.

12. Si hay presencia de exudado, o se planea realizar el tratamiento en 2 sesiones, se colocará un medicamento intraconducto (Hidróxido de Calcio, mezcla de Metronidazol, Ciprofloxacino y Minociclino) y se considerará la prescripción de medicamento sistémico.

13. Si no hay exudado purulento, o si se planeó un tratamiento de 1 sesión, se procederá con la obturación del o los conductos radiculares.

14. Una vez sellados los conductos, se tomará la radiografía correspondiente, para descartar que haya espacios sin obturar.

15. Se realizará la restauración definitiva utilizando coronas de acero o restauraciones a base de resina compuesta, ionómero de vidrio o amalgama. $(1,6)$

\section{Características ideales de un material de obturación radicular}

A continuación se describen las características que debe presentar el material de obturación radicular ideal: $(1,8,10,13,41,42)$
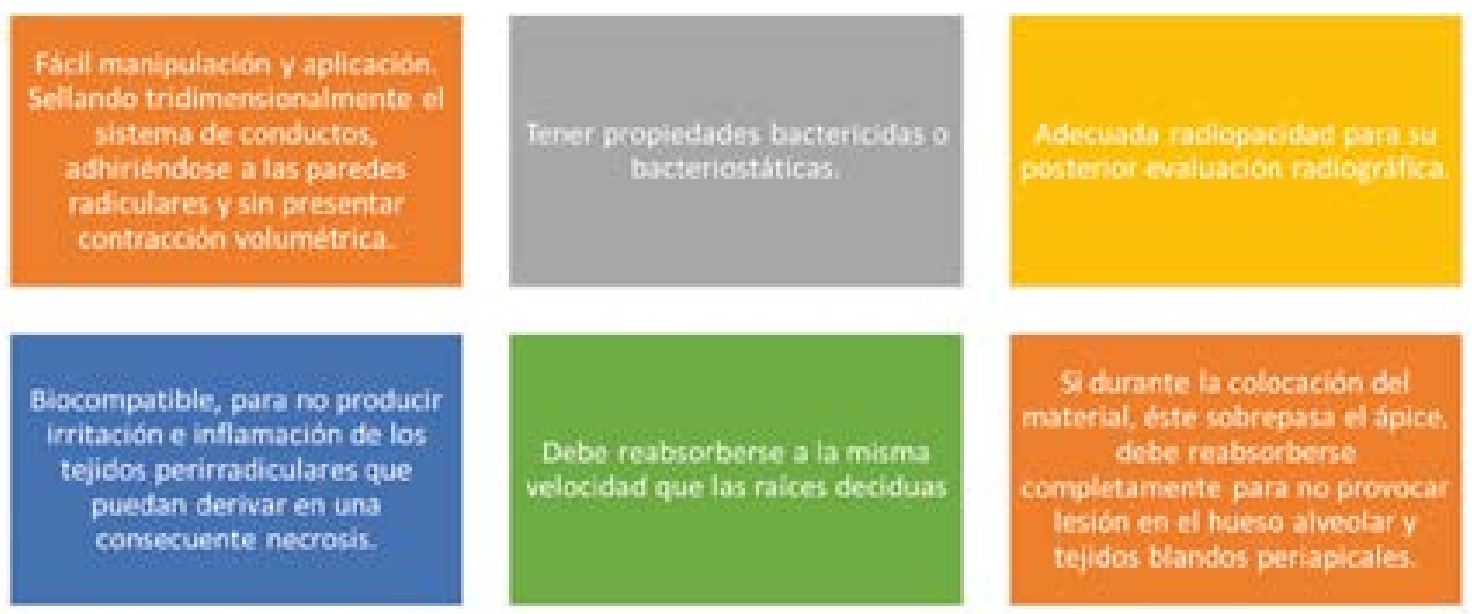

Sidumate la colocación del material, bstes sobrepasa el ápice. debe reabsorberse completamente para no prowoca Itesión en di hesso alveolary tejidos bhandos perapicales:

Figura 2. Características deseables en un material de obturación radicular. 


\section{Materiales de obturación disponibles}

\section{Materiales a base de Óxido de Zinc Eugenol} $\underline{(\mathrm{ZOE})}$

Los materiales a base de Óxido de Zinc con Eugenol se han utilizado como bases cavitarias, agentes cementantes, selladores de conductos, restauraciones provisionales y como material de obturación en pulpotomías y pulpectomías. Hasta 2008 era el único material recomendado por la Academia Americana de Odontología Pediátrica como obturador de conductos.(41) Antes del empleo del Hidróxido de Calcio, incluso era utilizado como agente de protección pulpar directa e indirecta, sin embargo se demostró que el óxido de Zinc con Eugenol en contacto directo con la pulpa produce inflamación crónica, seguida de necrosis.(43)

Fue Grossman quien lo introdujo en la terapia endodóntica en la década de 1930 siendo el primer material utilizado como sellador de conductos en combinación con la gutapercha,(44) Sweet lo introdujo como material obturador de conductos radiculares en la misma década y desde entonces ha sido el material más utilizado con éste fin. $(3,15,41,45,46)$

La presentación comercial de éste material es un polvo de color blanco, cuando no tiene colorantes, que contiene principalmente Óxido de Zinc, algunas partículas de relleno de sílice y alrededor de $1 \%$ de sales de zinc como acetato, propionato o sulfato, utilizadas como aceleradores; el líquido consta de un 85\% de eugenol, puede contener ácido acético o propiónico y pequeñas cantidades de agua.(47-49) El Eugenol es un fenol (2-metoxi-4-propenil-fenol) con propiedades analgésicas y antimicrobianas.(49) Las principales ventajas de éste material son precisamente sus capacidades sedantes y antimicrobianas. Se ha señalado que el Eugenol en contacto con los tejidos pulpares o perirradiculares es bastante irritante y potencialmente alergénico.(47) Cabe señalar también que el Eugenol interfiere con la polimerización de otros materiales utilizados en odontología (composites, sistemas adhesivos, etc.).(49) Con la llegada de nuevos materiales como el Ionómero de Vidrio y el uso cada vez más constante de compuestos a base de polímeros, la utilización de éste material se ha ido reduciendo. Sin embargo a pesar de la generación de nuevos materiales, su uso como material sellador de conductos aún tiene mucha relevancia y en odontopediatría es aún, para muchos, el material de primera elección para la obturación de conductos radiculares de la dentición primaria. $(14,42)$

El éxito clínico de éste material como obturador de conductos radiculares ha sido reportado previamente, obteniendo porcentajes de éxito clínico de entre el 82 y el $86 \%$, y hasta un $95 \%$. Otros autores han encontrado resultados significativamente menores $(78.5 \%)(46,51-53)$.

Su acción bactericida ha sido probada previamente,(54) Mussolino y col. probaron la eficacia bactericida del ZOE en pruebas de difusión en agar contra K. rizophila, E. faecalis, S. mutans, E. coli y S. aureus, en el que el ZOE demostró la mayor eficacia frente a K. rizophila y E. coli; frente a S. aureus y S. mutans demostró actividad similar al resto de los selladores utilizados en la prueba, solo obtuvo una diferencia significativamente menor contra E. faecalis.(22)

Estudios realizados para comparar la eficacia del ZOE frente a otros materiales han tenido diferentes resultados, por ejemplo el trabajo realizado por Trairatvorakul y Chunlasikaiwan(14), demostró que el éxito radiográfico del ZOE era significativamente inferior que el de Vitapex 
después de 6 meses de seguimiento; sin embargo después de 12 meses, el éxito radiográfico era similar con ambos materiales.

Diversos estudios en animales de experimentación han demostrado irritación de tejidos periapicales por acción del Óxido de Zinc Eugenol, se considera que el factor irritativo es consecuencia del uso de Eugenol(45, 55, 56), a la vez que posee una lenta reabsorción (menor que la radicular) en análisis radiográficos y se han reportado casos de desviación en la trayectoria de piezas de la segunda dentición como resultado de la no reabsorción del ZOE.(3, 14, 21, 42, 45, 46, 56, 57)

Con la finalidad de obtener una mayor tasa de éxito se agregó el formocresol a las composiciones de $\mathrm{ZOE}(42)$. Diversos estudios realizados desde los años 50’s han demostrado el éxito clínico de éste material, reportando tasas de éxito que van desde un 74 a 99\%.(6) El Formocresol fue introducido por Buckley a principios del siglo XVIII, en una fórmula que consistía en $19 \%$ de Formaldehído, 35\% de Cresol, 15\% de Glicerina y $31 \%$ de agua como vehículo(6); el Formaldehido es un gas muy inflamable e incoloro, con acción bactericida que suele usarse como desinfectante. En 2004, La Agencia Internacional para la Investigación de Cáncer clasificó al formaldehído como carcinogénico en humanos. Dado que en los componentes del Formocresol se encuentra el Formaldehído, su uso en odontología se ha puesto en duda. $(55,58,59)$

Materiales a base de Hidróxido de Calcio$\underline{\mathrm{Ca}(\mathrm{OH})_{2}}$

El Hidróxido de Calcio es otro de los materiales utilizados en odontología desde hace largo tiempo. $(47,56)$ Éste mineral, también fue introducido en 1930 por Hermann, cuando demostró la formación de dentina secundaria sobre pulpas amputadas cubiertas con éste material. (45) Diversos estudios realizados en ésa misma década apoyaron la formación de puentes dentinarios cuando se utilizaba Hidróxido de Calcio lo que lo impulsó como recubrimiento pulpar de elección. En odontopediatría se ha utilizado como material obturador durante el tratamiento de pulpotomía. $(47,56)$

$\mathrm{Su}$ peso molecular es de $74 \mathrm{~g} / \mathrm{mol}$, es ligeramente soluble en agua e insoluble en alcohol.(2, 60, 61) La mezcla de Hidróxido de Calcio con agua posee un $\mathrm{pH}$ fuertemente alcalino (alrededor de 12), lo que le confiere acción bactericida, además se considera que los osteoclastos y dentinoclastos reducen su actividad frente al Hidróxido de Calcio. $(2,47,56,60,62) \mathrm{Su}$ principal efecto biológico es la difusión de iones $\mathrm{Ca}+\mathrm{y} \mathrm{OH}$, ésta característica posee una acción caustica sobre los tejidos, lo que produce una zona inicial de necrosis.(2) En presencia de Dióxido de Carbono (CO2) el Hidróxido de Calcio se transforma por disociación en Carbonato de Calcio.(2)

En tratamientos de conductos, el Hidróxido de Calcio ha sido rutinariamente utilizado como material de restauración intermedia (en 2 citas). (63-66)

Comercialmente puede conseguirse de manera pura o se puede encontrar premezcladas en diferentes presentaciones comerciales, por ejemplo Calen (SS White $\left.{ }^{\circledR}\right)$, Pulpdent Temp Canal (Pulpdent Corporation $®)$ y Ultracal (Ultradent Products Inc. () , variando algunos componentes entre uno y otro y con diferentes concentraciones de Hidróxido de Calcio. Generalmente vienen en presentación de jeringa predosificada y poseen punta dispensadora lo cual facilita la colocación dentro del conducto. Éstas formulaciones se remueven con relativa facilidad de los conductos mediante la irrigación con Hipoclori- 
to de Sodio, ligera instrumentación y el empleo de agentes quelantes como el EDTA, aunque se ha demostrado que éstos materiales disminuyen la cantidad de túbulos dentinarios expuestos, lo cual puede afectar el sellado definitivo.(63)

Éstos materiales también son utilizados como agentes selladores de conductos en odontopediatría, demostrando una buena efectividad (13, $55,62,67)$ Los materiales a base de Hidróxido de Calcio tienen buena reabsorción cuando se extruyen del ápice.(41) Dentro de las desventajas que presenta, están una reabsorción más rápida en comparación con las raíces y, además se le atribuye ocasionar reabsorción radicular interna.(55)

El Hidróxido de Calcio también suele ser empleado como solución irrigadora, puede emplearse químicamente puro o en combinación con otros agentes antibacterianos como la Clorhexidina, para un mayor efecto bactericida.(40)

\section{Materiales a base de Yodoformo}

Los materiales a base de Yodoformo fueron introducidos por Walkhoff en 1928, estas formulaciones poseen capacidad antimicrobiana y una mejor reabsorción que los materiales a base de Óxido de Zinc Eugenol.(41, 45, 68) El Yodoformo es un polvo de color amarillento, poco soluble en agua, soluble en alcohol y éter, con un alto porcentaje de Yodo (97\%), que presenta potencial bactericida.(12)

A través de los años se han sugerido diversas composiciones a base de Yodoformo; las que mejores resultados han obtenido es la pasta KRI que consta de $(80.8 \%$ de Yodoformo, 4.8 de Alcanfor, $1.21 \%$ de Mentol y $2.025 \%$ de Paraclorofenol). $(6,21,41)$ En el estudio realizado por Bawazir, esta pasta demostró menor microfil- tración que el ZOE.(69) Otra de las ventajas de ésta clase de materiales es su rápida absorción cuando se extruye del ápice, sin afectar al órgano permanente.(58) Una desventaja importante es qué la velocidad de reabsorción es mayor que la de las raíces quedando espacios vacíos antes de la exfoliación de la pieza.(55) La Pasta Maisto (Yodoformo, Alcanfor, Mentol, Paraclorofenol, Óxido de Zinc, Lanolina y Timol), es una modificación a la pasta KRI con la intención de mejorar el grado de reabsorción de la composición. Estudios demostraron que éste material es seguro cuando se extruye fuera del ápice, presentando una reabsorción que va de dos semanas a tres meses, además se considera que la reabsorción del material intraconducto aún es más rápida que la de la raíz.

Otra formulación que puede considerarse dentro de este grupo es la Pasta Guedes-Pinto (Yodoformo, Paraclorofenol alcanforado y Rifocort $\left.{ }^{\circledR}\right)$. (70) Algunos estudios, revelan una buena actividad antibacteriana de esta formulación contra microorganismos que comúnmente se encuentran en infecciones endodónticas de dientes de la primera dentición. $(54,71)$

Además de la desventaja de su rápida absorción,(56) las pastas a base de Yodoformo, poseen la característica de pigmentar los dientes, también se ha propuesto su potencial alergénico, causan irritación de tejidos periapicales y necrosis del cemento radicular; $(55,56,67)$ además de las desventajas propias de los derivados fenólicos.

\section{$\underline{\text { Otros materiales }}$}

En la búsqueda del material de obturación ideal, se han desarrollado combinaciones a partir de los ingredientes ya mencionados (ZOE, Hidróxido de Calcio y Yodoformo) con la finalidad de 
mejorar sus propiedades y aminorar sus efectos secundarios. Los siguientes materiales son los que han obtenido mejores resultados:

\section{Hidróxido de Calcio con Yodoformo}

Comercialmente se distribuye con los nombres comerciales de Vitapex (Neo Dental International Inc. $\left.{ }^{\circledR}\right)$, Diapex (Daident Group International $($ ), Metapex (Meta Biomed CO. LTD®), entre otros. Su composición es la siguiente: Hidróxido de Calcio, Yodoformo, aceite de silicón como vehículo oleoso y material inerte.(41) Posee un $\mathrm{pH}$ cercano al neutro en un registro de tiempo de 60 días.(62) Gracias a su contenido de silicón éste material no endurece, lo que en caso de ser necesario facilita su remoción y reobturación, su presentación comercial facilita la técnica de empleo, lo que lo hace un material cómodo y rápido de utilizar.

Posee actividad bactericida in Vitro con respecto a microorganismos frecuentemente presentes en la microflora de la región apical como Staphylococcus aureus, Enterococcus faecalis, Pseudomonas aureginosa, Bacillus subtilis y Candida albicans, en pruebas de contacto directo el efecto antimicrobiano se manifestó después de las primeras 24h; sin embargo en pruebas de difusión en agar no se encontró actividad bactericida. (54)

Ésta combinación ha demostrado un éxito clínico de hasta $100 \%$, lo que hace sugerir a algunos autores que es el material más cercano al ideal. $(15,46)$ Por ejemplo el estudio realizado por Mortazavi,(46) encontraron una tasa de éxito clínico de $100 \%$ para Vitapex mientras que para el ZOE fue de $78.5 \%$ después de 16 meses de evaluación; además Vitapex demostró completa reabsorción del material extruido durante los 3 meses posteriores al tratamiento. En el estudio realizado por Subramaniam y colaboradores(72) también se encontró un éxito de $100 \%$ para un material a base de Hidróxido de Calcio con Yodoformo (Metapex); sin embargo el Óxido de Zinc Eugenol, también alcanzó un porcentaje elevado de éxito (93\%). En el estudio realizado por Grupta, el éxito clínico de Vitapex fue de 90. $4 \%$ contra un $85.7 \%$ del ZOE.(14) Bawazir demostró que el Vitapex presenta menor rango de microfiltración en comparación con el ZOE y la pasta KRI.(69)

Una de las principales características del Vitapex es su capacidad de reabsorción, ésta propiedad como ya se mencionó es de sumo interés cuando el material obturador sobrepasa el ápice y queda suspendido en los tejidos perirradiculares; algunos ensayos clínicos sugieren que el material que se extruye del ápice completa su reabsorción entre 2 semanas a 6 meses, $(15,45$, 46) en contraparte, algunos autores manejan que la velocidad de reabsorción intracanal también es acelerada, más que la velocidad de reabsorción de las raíces, por lo que plantean que puede ser condicionante para el éxito del tratamiento. $(13,45,55)$

\section{Hidróxido de Calcio con Óxido de Zinc}

Dentro de éste grupo podemos encontrar el Sealapex (Kerr Corporation $\left.{ }^{\circledR}\right)$, en presentación de dos pastas, se compone de Hidróxido de Calcio, Sulfato de Bario, Óxido de Zinc, Dióxido de Titanio, Estearato de Zinc, salicilato de isobutilo, salicilato de metilo y pigmentos.(22)

Fue creado como material sellador de conductos por inducir el cierre apical mediante la deposición de minerales, entre sus ventajas encontramos su biocompatibilidad y una buena capacidad de sellado, sin embargo, la solubilidad de este material es su principal desventaja. $(73,74)$ 
En un lapso de 60 días, presenta un pH aproximado al neutro, esto puede reducir el grado de irritación hacia los tejidos adyacentes, pero también puede decrecer su efecto bactericida.(62)

En un estudio relizado por Sari y colaboradores(13), dieron seguimiento a tratamientos realizados con Sealapex durante 3 años, ellos obtuvieron un tasa de éxito de $92.3 \%$, también observaron mediante análisis radiográficos que en el $58 \%$ de los casos en los que la raíz fue sobreobturada, el material mostró completa reabsorción a los 12 meses de evaluación.

La actividad bactericida de éste material fue probada en el estudio realizado por Mussolino de Queiroz y colaboradores. Los resultados para Sealapex fue una significativa menor actividad en contra de K. rhizophila y E. coli que el ZOE, frente a E. faecalis Sealapex tuvo mucha mayor actividad que el ZOE, y frente a $S$. mutans y $S$ auereus los resultados fueron similares.(22)

En diversos estudios realizados, se ha comprobado la citotoxicidad de Sealapex, así como de otros selladores a base de Hidróxido de Calcio, estudios in Vitro confirman el efecto tóxico sobre los osteoblastos, aunque no se confirman las causas de ésta afectación, la cual probablemente sea debido a otros componentes de la formulación.

Con respecto al sellado que ofrece Sealapex, de acuerdo con el estudio realizado por Vasconcelos(74) el grado de filtración aumenta progresivamente, resultados que concuerdan con otros autores.

Endoflas FS (Sanlor Laboratories®) es el nombre comercial que recibe ésta formulación que intenta congregar las ventajas de sus componentes: Óxido de Zinc, Sulfato de Bario, Pentaclorofeno, Eugenol y una mínima cantidad de Hidróxido de Calcio. $(15,55)$ Se presenta comercialmente en constitución polvo-líquido lo cual implica una ligera desventaja con respecto a la técnica de obturación y el tiempo de trabajo.

Estudios realizados in Vitro han demostrado su eficacia en contra de Enterococcus faecalis y Candida albicans, demostrando también que su mayor efecto antimicrobiano lo alcanza dentro de las primeras $24 \mathrm{hrs}$. disminuyendo considerablemente después de éste plazo.

Éste material también ha demostrado gran eficacia (alrededor de 90\%) en estudios clínicos realizados en los últimos años, encontrándose pocos casos reportados de reincidencia del proceso infeccioso, afecciones en piezas permanentes o erupción con malposición. $(72,75,76)$

En un estudio realizado por Ramar(15) se demostró un $100 \%$ de reabsorción del material extruido fuera del conducto radicular, así como el 100\% de los casos, demostró disminución en las zonas radiolúcidas a nivel de furca durante 9 meses de examinación. Otros estudios han demostrado una tasa de éxito de $70 \%$ después de 4 años del tratamiento.(21)

Esta pasta también posee la capacidad de ser reabsorbida rápidamente cuando se extruye del ápice.(55) Endoflas F.S. presentó una tasa de éxito mayor $(83 \%)$ cuando la obturación se realizó adecuadamente o subobturación, contra un 58\% cuando se produjo una sobreobturación. Otros estudios demostraron una tasa de éxito de hasta un $91 \%$ cuando hubo subobturación del material y $76 \%$ cuando se presentó sobreobturación(6).

En 1995 se reportó acerca la toxicidad de éste material en tejido conectivo subcutáneo de ratas, durante las primeras 48 hrs. y hasta los 7 días después de los cuales el grado de inflamación tisular fue decreciendo hasta que 3 meses después no se encontraron signos de edema.(77) 


\section{Conclusiones}

La pulpectomía, independientemente de la técnica que se emplee para realizarla, es un procedimiento clínico que ha demostrado un alto grado de éxito, lo que nos indica que es una técnica válida para evitar la extracción de órganos dentarios afectados.

Es importante mencionar que éste éxito clínico depende de manera significativa del material que es utilizado para realizar la obturación de los conductos radiculares. Si bien, la gran mayoría de los materiales aquí presentados han de- mostrado ser eficaces para la realización de este tipo de tratamientos, las pastas yodoformadas con hidróxido de calcio han sido encontradas como uno de los mejores materiales para realizar este tipo de procedimientos.

Sin embargo, es necesario mencionar que todos los materiales que se ocupan hoy en día para este fin, presentan alguna deficiencia en particular, lo que motiva al estudio más exhaustivo para conseguir el desarrollo de materiales con mejores características y mejores resultados a largo plazo.

\section{Referencias}

1. National Guideline C. Guideline on pulp therapy for primary and immature permanent teeth Rockville MD: Agency for Healthcare Research and Quality (AHRQ); [10/3/2012]. Available from: http://www.guidelines.gov/content. aspx?id=15252.

2. Gunnar GAB. Pulpectomy: Studies on outcome. Endodontic Topics. 2003;5.

3. Pinky C, Shashibhushan KK, Subbareddy VV. Endodontic treatment of necrosed primary teeth using two different combinations of antibacterial drugs: an in vivo study. Journal of the Indian Society of Pedodontics and Preventive Dentistry. 2011;29(2):121-7.

4. Takushige T, Cruz EV, Asgor Moral A, Hoshino E. Endodontic treatment of primary teeth using a combination of antibacterial drugs. Int Endod J. 2004;37(2):132-8.

5. Prabhakar AR, Sridevi E, Raju OS, Satish V. Endodontic treatment of primary teeth using combination of antibacterial drugs: an in vivo study. Journal of the Indian Society of Pedodontics and Preventive Dentistry. 2008;26 Suppl 1:S5-10.

6. Stallaert KM. A Retrospective Study of Root Canal Therapy in Non-Vital Primary Molars: University of Toronto; 2011.

7. Hargreaves KM, Berman LH, Cohen S. Cohen. Vías de la Pulpa: Elsevier Health Sciences Spain; 2011.

8. Rodd H. D. WPJ. UK National Guidelines in Pediatric Dentistry: Pulp therapy for Primary Molars. International Journal of Pediatric Dentistry. 2006;16.

9. Koch G. Pediatric Dentistry. A Clinical Approach. Wiley-Blacwell. 2009.

10. Imamura Y, Tanaka Y, Nagai A, Yamashita K, Takagi Y. Self-sealing ability of OCP-mediated cement as a deciduous root canal filling materia. Dent Mater J. 2010;29(5):582-8.

11. Aminabadi NA, Farahani RM, Gajan EB. Study of root canal accessibility in human primary molars. J Oral Sci. 2008;50(1):69-74.

12. Salas ME. La pasta iodoformada como tratamiento del absceso dentoalveolar crónico reagudizado. Caso clínico. Revista Odontológica de los Andes. 2011;6(1):67-75.

13. Sari S, Okte Z. Success rate of Sealapex in root canal treatment for primary teeth: 3-year follow-up. Oral surgery, oral medicine, oral pathology, oral radiology, and endodontics. 2008;105(4):e93-6.

14. Trairatvorakul C, Chunlasikaiwan S. Success of pulpectomy with zinc oxide-eugenol vs calcium hydroxide/iodoform paste in primary molars: a clinical study. Pediatric dentistry. 2008;30(4):303-8.

15. Ramar K, Mungara J. Clinical and radiographic evaluation of pulpectomies using three root canal filling materials: an in-vivo study. Journal of the Indian Society of Pedodontics and Preventive Dentistry. 2010;28(1):25-9. 
16. Bhandari SK, Prajapati U. Root canal obturation of primary teeth: disposable injection technique. Journal of the Indian Society of Pedodontics and Preventive Dentistry. 2012;30(1):13-8.

17. Shenkin JD. Pulpectomy of necrotic primary teeth may be an effective tool in managing the primary dentition. The journal of evidence-based dental practice. 2012;12(1):39-40.

18. Gesi A, Hakeberg M, Warfvinge J, Bergenholtz G. Incidence of periapical lesions and clinical symptoms after pulpectomy--a clinical and radiographic evaluation of 1- versus 2-session treatment. Oral surgery, oral medicine, oral pathology, oral radiology, and endodontics. 2006;101(3):379-88.

19. Barrios ZC. Prevalencia de infecciones de origen pulpar en los niños atendidos en el Servicio de Odontopediatría del Instituto Autónomo Hospital Universitario de los Andes, Mérida, Venezuela. Revista Odontológica de los Andes. 2011;6(1):42-51.

20. Lopez-Marcos JF. Aetiology, classification and pathogenesis of pulp and periapical disease. Med Oral Patol Oral Cir Bucal. 2004;9 Suppl:58-62; 52-7.

21. Costa Sales Cunha CB BR, Guimarães Primo L. Soluções irrigadoras e Materiais Obturadores Utilizados na Terapia Endodôntica de Dentes Decíduos. Pesquisa Brasileira em Odontopediatria e Clínica Integrada. 2005;5(1).

22. Queiroz AM, Nelson-Filho P, Silva LA, Assed S, Silva RA, Ito IY. Antibacterial activity of root canal filling materials for primary teeth: zinc oxide and eugenol cement, Calen paste thickened with zinc oxide, Sealapex and EndoREZ. Brazilian dental journal. 2009;20(4):290-6.

23. Faria G, Nelson-Filho P, Freitas AC, Assed S, Ito IY. Antibacterial effect of root canal preparation and calcium hydroxide paste (Calen) intracanal dressing in primary teeth with apical periodontitis. J Appl Oral Sci. 2005;13(4):351-5.

24. Giral T. Lesiones traumáticas en dentición primaria. Perinatología y Reproducción Humana. 2009;23(2):108-15.

25. García Ballesta C, Pérez Lajarín L, Castejón Navas I. Prevalencia y etiología de los traumatismos dentales: Una revisión. RCOE. 2003;8:131-41.

26. Fuente-Hernández Jdl, González de Cossío M, Ortega-Maldonado M, Sifuentes-Valenzuela MC. Caries y pérdida dental en estudiantes preuniversitarios mexicanos. Salud Pública de México. 2008;50:235-40.

27. Vera-Hermosillo H. Niñas y niños libres de caries en México. Prueba piloto en Tlapa, Guerrero. Revista de la Asosiación Dental Mexicana. 2010;67(5):217-22.

28. Irigoyen ME, Mejia-Gonzalez A, Zepeda-Zepeda MA, Betancourt-Linares A, Lezana-Fernandez MA, Alvarez-Lucas CH. Dental caries in Mexican schoolchildren: A comparison of 1988-1989 and 1998-2001 surveys. Med Oral Patol Oral Cir Bucal. 2012;17(5):e825-32.

29. Petersen PE. World Health Organization global policy for improvement of oral health--World Health Assembly 2007. Int Dent J. 2008;58(3):115-21.

30. Villalobos-Rodelo JJ, Medina-Solis CE, Molina-Frechero N, Vallejos-Sanchez AA, Pontigo-Loyola AP, Espinoza-Beltran JL. [Dental caries in schoolchildren aged 6-12 years in Navolato, Sinaloa, Mexico: experience, prevalence, severity and treatment needs]. Biomedica. 2006;26(2):224-33.

31. Segovia-Villanueva A, Estrella-Rodríguez R, Medina-Solís CE, Maupomé G. Severidad de caries y factores asociados en preescolares de 3-6 años de edad en Campeche, México. Revista de Salud Pública. 2005;7:56-69.

32. Moreno-Canseco D. Prevalencia de caries de la infancia temprana y nivel socioeconómico familiar. Revista Odontológica Mexicana. 2011;15(2):96-102.

33. AAPD. Policy on early childhood caries (ECC): classifications, consequences, and preventive strategies. Pediatric dentistry. 2008;30(7 Suppl):40-3.

34. OMS. Nota Informativa no. 318 2007. Available from: http://www.who.int/mediacentre/factsheets/fs318/es/index. html.

35. Pérez LS, Camacho MEI, Frechero NM. Enfermedades dentales de alta prevalencia en México. Contribución de la línea de cariología y otras alteraciones dentales. Revista de Ciencias Clínicas. 2009;10:70-85.

36. Islas-Zarazúa R, Pontigo-Loyola A, Medina-Solís C, Márquez-Corona M, Rosa-Santillana RDl, Vallejos-Sánchez A. Prevalencia de caries dental en escolares de cuatro localidades hidalguenses. Memorias del VII Congreso Internacional de 
Odontología Multidisciplinaria, II Concurso Mexicano e Iberoamericano de Investigación Clínica en Odontología y 1st Aztec Award for Clinical Research in Dentistry San Luis Potosí, SLP. 2009.

37. Suarez-Ortega S, Medina-Solis C, Pontigo-Loyola A, Mendoza-Rodríguez M, Marquez-Corona M, Vallejos-Sánchez A. Caries dental en escolares de 5-12 años de edad de Zempoala Hidalgo. Memorias del XXI Congreso Nacional e Internacional de Posgrado e Investigación en Odontología y Reunión Anual de la división Mexicana de la IADR Acapulco, Guerrero, México. 2009.

38. Tunc ES, Bayrak S. Usage of white mineral trioxide aggregate in a non-vital primary molar with no permanent successor. Aust Dent J. 2010;55(1):92-5.

39. American Academy on Pediatric Dentistry Clinical Affairs Committee-Pulp Therapy s, American Academy on Pediatric Dentistry Council on Clinical A. Guideline on pulp therapy for primary and young permanent teeth. Pediatric dentistry. 2008;30(7 Suppl):170-4.

40. Rahde NdM, Figueiredo JAP, Oliveira EPM. Influence of calcium hydroxide points on the quality of intracanal dressing filling. Journal of Applied Oral Science. 2006;14:219-23.

41. Barja-Fidalgo F, Moutinho-Ribeiro M, Oliveira MAA, Oliveira BH, \#237, de s. A Systematic Review of Root Canal Filling Materials for Deciduous Teeth: Is There an Alternative for Zinc Oxide-Eugenol? ISRN Dentistry. $2011 ; 2011$.

42. Praveen P. A review of obturating materials for primary teeth. Streamdent. 2011;20(20).

43. McDonald RE, Avery DR. Odontología pediátrica y del adolescente: Elsevier - Health Sciences Division; 1996.

44. Marín-Bauza GA, Silva-Sousa YTC, Cunha SAd, Rached-Junior FJA, Bonetti-Filho I, Sousa-Neto MD, et al. Physicochemical properties of endodontic sealers of different bases. Journal of Applied Oral Science. 2012;20:455-61.

45. Gupta S, Das G. Clinical and radiographic evaluation of zinc oxide eugenol and metapex in root canal treatment of primary teeth. Journal of the Indian Society of Pedodontics and Preventive Dentistry. 2011;29(3):222-8.

46. Mortazavi M, Mesbahi M. Comparison of zinc oxide and eugenol, and Vitapex for root canal treatment of necrotic primary teeth. Int J Paediatr Dent. 2004;14(6):417-24.

47. O’Brien WJ. Dental Materials and their selection. 3rd ed: Quintessence Publishing Co, Inc; 2002.

48. Anusavice KJ. Phillip’s Science of Dental Materials. 11th ed: Saunders Elsevier; 2003.

49. Macchi RL. Materiales Dentales: Panamericana; 2007.

50. Lioni CB. Agentes selladores. Relación entre la velocidad de reabsorción y la biocompatibilidad. Electronic Journal of Endodontics Rosario. 2010;2.

51. Primosch RE, Ahmadi A, Setzer B, Guelmann M. A retrospective assessment of zinc oxide-eugenol pulpectomies in vital maxillary primary incisors successfully restored with composite resin crowns. Pediatric dentistry. 2005;27(6):470-7.

52. Ozalp N, Saroglu I, Sonmez H. Evaluation of various root canal filling materials in primary molar pulpectomies: an in vivo study. American journal of dentistry. 2005;18(6):347-50.

53. Pinto DN, de Sousa DL, Araujo RB, Moreira-Neto JJ. Eighteen-month clinical and radiographic evaluation of two root canal-filling materials in primary teeth with pulp necrosis secondary to trauma. Dental traumatology : official publication of International Association for Dental Traumatology. 2011;27(3):221-4.

54. Amorim LdFGd, Toledo OAd, Estrela CRdA, Decurcio DdA, Estrela C. Antimicrobial analysis of different root canal filling pastes used in pediatric dentistry by two experimental methods. Brazilian dental journal. 2006;17:317-22.

55. Chawla HS, Setia S, Gupta N, Gauba K, Goyal A. Evaluation of a mixture of zinc oxide, calcium hydroxide, and sodium fluoride as a new root canal filling material for primary teeth. Journal of the Indian Society of Pedodontics and Preventive Dentistry. 2008;26(2):53-8.

56. Silva LABd, Leonardo MR, Oliveira DSBd, Silva RABd, Queiroz AMd, Hernández PG, et al. Histopathological evaluation of root canal filling materials for primary teeth. Brazilian dental journal. 2010;21:38-45.

57. Farhad AR, Hasheminia S, Razavi S, Feizi M. Histopathologic evaluation of subcutaneous tissue response to three endodontic sealers in rats. J Oral Sci. 2011;53(1):15-21.

58. Srinivasan V, Patchett CL, Waterhouse PJ. Is there life after Buckley's Formocresol? Part I -- a narrative review of alternative interventions and materials. Int J Paediatr Dent. 2006;16(2):117-27. 
59. IARC. IARC Classifies formaldehyde as carcinogenic to humans 2004. Available from: http://www.iarc.fr/en/mediacentre/pr/2004/pr153.html.

60. Chu Zhu SMPP, Bernardo; Labajo González, Elena; Santiago Sáez, Andrés; García Marín, Fernando. Lesiones causadas por extrusión de hidróxido de calcio al periápice: Causas y recomendaciones de actuación. Científica Dental. 2011;8(2):61-7. 61. Soares IJ, Goldberg F. Endodoncia: Técnica y fundamentos: Médica Panamericana; 2002.

62. Nunes ACGP, Rocha MJdC. Hydroxyl and calcium ions diffusion from endodontic materials through roots of primary teeth - in vitro study. Journal of Applied Oral Science. 2005;13:187-92.

63. Victorino FR, Bramante CM, Zapata RO, Casaroto AR, Garcia RB, Moraes IG, et al. Removal efficiency of propolis paste dressing from the root canal. J Appl Oral Sci. 2010;18(6):621-4.

64. Murad C, Fariniuk LF, Fidel S, Fidel RA, Sassone LM. Bacterial leakage in root canals filled with calcium hydroxide paste associated with different vehicles. Brazilian dental journal. 2008;19(3):232-7.

65. Soares JA, Leonardo MR, Silva LA, Tanomaru Filho M, Ito IY. Effect of biomechanical preparation and calcium hydroxide pastes on the antisepsis of root canal systems in dogs. J Appl Oral Sci. 2005;13(1):93-100.

66. Lana PE, Scelza MF, Silva LE, Mattos-Guaraldi AL, Hirata Junior R. Antimicrobial activity of calcium hydroxide pastes on Enterococcus faecalis cultivated in root canal systems. Brazilian dental journal. 2009;20(1):32-6.

67. Alvares AC. Pulpectomías: Vitapex y Ultracal otra alternativa de material de relleno. Publicación Científica Facultad de Odontología UCR. 2006;8.

68. Pabla T, Gulati MS, Mohan U. Evaluation of antimicrobial efficacy of various root canal filling materials for primary teeth. Journal of the Indian Society of Pedodontics and Preventive Dentistry. 1997;15(4):134-40.

69. Bawazir OA, Salama FS. Apical microleakage of primary teeth root canal filling materials. J Dent Child (Chic). 2007;74(1):46-51.

70. Guedes-Pinto A, Paiva J, Bozzola J. Tratamento endodôntico de dentes decíduos com polpa mortificada. Revista da Associacao Paulista de Cirurgioes Dentistas. 1981;3:240-5.

71. Vargas-Ferreira F, Angonese MP, Friedrich HC, Weiss RDN, Friedrich RS, Praetzel JR. Antimicrobial action of root canal filling pastes used in deciduous teeth. Revista Odonto Ciência. 2010;25:65-8.

72. Subramaniam P, Gilhotra K. Endoflas, zinc oxide eugenol and metapex as root canal filling materials in primary molars-a comparative clinical study. J Clin Pediatr Dent. 2011;35(4):365-9.

73. Gomes-Filho JE, Moreira JV, Watanabe S, Lodi CS, Cintra LTA, Dezan Junior E, et al. Sealability of MTA and calcium hydroxidecontaining sealers. Journal of Applied Oral Science. 2012;20:347-51.

74. Vasconcelos BC, Bernardes RA, Duarte MA, Bramante CM, Moraes IG. Apical sealing of root canal fillings performed with five different endodontic sealers: analysis by fluid filtration. J Appl Oral Sci. 2011;19(4):324-8.

75. Moskovitz M, Sammara E, Holan G. Success rate of root canal treatment in primary molars. J Dent. 2005;33(1):41-7.

76. Moskovitz M, Yahav D, Tickotsky N, Holan G. Long-term follow up of root canal treated primary molars. Int J Paediatr Dent. 2010;20(3):207-13.

77. Mittal M, Chandra S. Comparative tissue toxicity evaluation of four endodontic sealers. J Endod. 1995;21(12):622-4.

Recibido: 03-03-2014

Aceptado: 21-05-2014

Correspondencia: Cuevas Suárez Carlos Enrique,Profesor Investigador. Área Académica de Odontología. Instituto de Ciencias de la Salud. Universidad Autónoma del Estado de Hidalgo. Instituto de Ciencias de la Salud, Circuito Ex-Hacienda La Concepción Km. 1.5; Municipio San Agustín Tlaxiaca, Hidalgo, México. C.P. 42160 Tel. 01 (771) 7172000 Ext. 5112 carlosecsuarez@gmail.com 